\title{
COLLECTION OF FOSSIL VERTEBRATES FOR THE SASKATCHEWAN MUSEUM OF NATURAL HISTORY, 1986
}

TIM T. TOKARYK, Earth Sciences Program, Saskatchewan Museum of Natural History, Wascana Park, Regina, Saskatchewan. S4P 3V7

During 1986 the staff members of the museum prospected several areas previously inspected and a few not reported on for a number of years (permit 86-3P).

In early July Dr. John Storer and I were in the Shaunavon area to wash additional sediments from our Late Cretaceous (65 million years ago) mammal locality (SMNH Loc. 72F08-0012) and to prospect more of the Frenchman River Valley area. ${ }^{1}$ Before this a brief stop was made at Old Man on His Back Plateau (SMNH Loc. 72F03-0004) south of Robsart which had previously been reported on for its fossils in 1950 and 1961.23 The exposures there were still visible and a number of fossils were collected from these Frenchman Formation sediments. One of the specimens collected is an abnormally large (for its time) marsupial partial mandible. Mammalian remains from the "Age of Dinosaurs" are not commonly found, mostly because of their diminutive size; the recovery of this specimen sparked interest even more. This digression from the collection objective was brief, and we collected two burlap sacks full of surface matrix to be microscopically picked later at the Museum.

A week was spent at the "Gryde" locality carrying matrix to the truck to be transported to the Frenchman River for soaking and washing. This material will take about a year to process and study.

Several trips were made to the Unity area mostly to give tours to high school students under the supervision of Mr. Bob Eltom, and to staff members of the Tyrrell Museum of Palaeontology (Drumheller, Alberta), including the director Dr. Emlyn Koster and Drs. Philip J. Currie and Dennis Brahman. Nothing articulate or spectacular was found in these sediments ( 70 to 75 million years old) though a few small theropod elements were collected. Identification of these and other specimens will add to the local fauna.

In early August Dr. John Storer escorted Dr. Donald Prothero of Occidental College, Los Angeles, into the Lac Pelletier area to conduct paleomagnetic sampling. This research should, if it turns out successfully, assist greatly in a more precise dating of vertebrate fauna found in the area. The present assignment is the Late Eocene (about 38-40 million years ago).

In early September Dr. Storer, Marilyn Laframboise, Don Jeffrey and I were in Morgan Creek Badlands (also known as Killdeer Badlands) to collect additional remains of vertebrates from the Frenchman Formation. An unpublished report by Dr. Dale Russell of the National Museum of Natural Sciences (Ottawa) roughly sketches the fossil potential of the area. ${ }^{4}$ Though geographically small (only 2.5 square miles) the area has many exposures. A week of introduction to these badlands was to be followed up in succeeding field seasons, but uncooperative weather kept us in camp except for about a day and a half of reasonable prospecting. There were a number of fossiliferous localities including one which yielded the 
